the bulk of my specimens greatly resemble those of the above fossil genus. Professor Agassiz has written to me to say that the discovery of the Ceratodus forsteri is of the greatest importance, and that he (Prof. Agassiz) is "amazed" at it. By this mail two of these interesting strangers (with intestines) will be shipped to England, as a present from Prof. A. M. Thomson to Prof. Owen, another by Mr. Ramsay to Dr. Sclater. I am glad to see that my friend Ramsay has complied with Dr. Sclater's request, and ceased classing the Ceratodus as "Salmon," which he confesses to have done frequently before. Mr. George Masters, the assistant curator of the Museum, is now at Gayndah, with appliances to catch the fish, and he will, if possible, send some alive to Sydney and to the Zoological Society of London.

Sydney, Sept. 7 Gerard KREFFT

\section{The British Museum Collections}

As it is proposed to remove the Natural History collections from the British Museum to Kensington, I hope care will be taken to make the collections as serviceable as possible to students. In particular the British Department might, with great gain to all, be extended and improved. There is now but one small room devoted to British zoology, and this interesting branch of science is poorly represented by a selection of species not always well chosen nor even strictly indigenous. Still, imperfect as it is, I believe this is the only attempt to present a comprehensive view of the British fauna in London. In the new buildings it is much to be desired that a large and well-lighted gallery should be devoted to the zoology of the British Islands, and as complete a collection as possible exhibited. The specimens should be labelled with local as well as scientific naines, and, when desirable, short interesting particulars might be given, as on the labels of the art collection at South Kensington. I think no part of the museum would be so well frequented or so generally appreciated by the public. When the labour of removing the collections is over, I hope we may be furnished with catalogues of different departments, with notes of the time and mode of acquisition, \&c., of the most important specimens. If begun for the British collections, it might afterwards be extended to the rest of the museum. The nation, which possesses such truly choice and extensive collections, ought to take care that the advantages to be reaped from them are fully developed and placed within the reach of all.

A. W.L.

\section{Glass Floats off the I:Ale of Lewis}

THE glass globes to which you refer as baving been found on the shores of Lewis, are no doubt fishing floats. The Bergen fishermen have recently begun to use such balls as floats for their nets, and they are occasionally picked up in the North Sea. Those which have been brought to this office were empty, i.e, contained no liquid, and bore no distinguishing mark at all. They were picked up about too miles S.W. of the Loffoden Islands.

I I6, Victoria Street, London, S.W. RoberT H. Scotr

P.S.-If any of the globes are sent to me, I shall be happy to inquire in Norway about them, and return them, after inspection, to their owners.

\section{The Milky Way}

YouR correspondent, Mr. Jeremiah, after quoting the words of the Llangadock "Oracle," adds, "meaning that the wind will blow from that quarter." Did Mr. Jeremiah interpret the man's meaning correctly? If so it is at variance with a popular belief in Hampshire, viz, that in whichever way the Milky Way may be seen over night, the wind is sure to blow across it, or at right angles to it on the following day. HENRY REEKS

\section{The Cockroach}

IN some ships infested with these insects, sailors frequently complain of having their toe and finger nails, and the hard parts of the soles of the feet and palms of the hands, nibbled by them. The men have exhibited to me their nails and skin, which had the appearance of having been attacked. I can vouch for the following, as I was the unhappy subject of it. On returning from a shooting excursion in salt swamps in tropical Australia, with my feet blistered and sodden, I was put to sleep in a room swarming with cockroaches (the small species). The night was intensely hot, and my feet were exposed. I had slept soundly for some hours, when an intolerable itching and irritation about my feet awoke me. I felt these objectionable insects running over and gnawing at my feet. On striking a light, I found they had attacked the skin, and entirely eaten it away from a large blister, leaving a raw place as large as a shilling. I slept again, and in the morning found they had completed the work, and established a painful sore. The whole of the hard skin on the heel was also eaten down to the pink flesh. The nails were not attacked. I have now, at a distance of four years' time, bluish scars on the skin.

Mill Hill, Nov, is

Arthur Nicols

I HAVE to thank the Rev. W. Houghton for his references on this subject, and to explain that $I$ wrote Aristotle inadvertently for Aristophanes. My only objection to adopting $\sigma^{i} \lambda \phi \eta$ as the Greek equivalent for our cockroach is that the unpleasant smell which is mentioned as a characteristic of the former, is not particularly marked in the latter. If we adopt the view that the cockroach was known to the ancients, we must, of course, reject Gilbert White's story of its American origin, and, as he thought, its recent introduction into England.

C. J. R

\section{KAIETEUR WATERFALL, DEMERARA}

THE great Kaieteur Fall, recently discovered by $\mathrm{Mr}$. Brown, has a clear descent, according to barometrical observations, taken simultaneously by $\mathrm{Mr}$. Brown at the bottom, and by Mr. Mitchell, at the top, of 750 feet. Above, the Potaro glides smoothly in a slight depression of the table of conglomerate sandstone, and disappears over the edge in a body, which is estimated at eighty yards in width, and of depth uncertain in the centre, but shallowing rapidly towards either bank. When the Fall was discovered in April, the rocky channel was completely covered, and the stream must have had a width of, at least, 100 yards. During the summer it is diminishing in volume, and, as the Indians state that it will continue to do so till October, only the central and deeper portion, about one-third of the whole, will then remain. The best time, therefore, for a visit is in spring, at the end of what appears to be the rainy season of this elevated tract.

As the Fall was seen by the exploring party who discovered it, nothing can be imagined more beautiful The central portion, which is never dry, forms a small horse-shoe, or re-entering angle, and the water in this part preserves its consistency for a short distance from the edge. But everywhere else, and here also at a few feet from the top, all semblance of water disappears ; it breaks up, or blossoms, into fine foam or spray, which descends in the well-known rocket-like forms of the Staubbach and similar waterfalls, but multiplied a thousand times, into a small dark pool, over a semicircular curtain. The cavern behind the Fall is the home of thousands of swallows, which issue from it in the morning, and may be seen returning in their multitude at night. The Fall itself is one vast descending column of a fine, dry-looking, snow-white substance, bearing a resemblance in colour and consistency to the snow of an avalanche, but surpassing all avalanches in size and in the beauty of the forms taken by the material as it falls. Rainbows of great splendour were observed, one from the front of the Fall in the morning, one from the summit in the afternoon; but this last reverted, forming a coloured loop or ring, into which the whole mass seemed to precipitate itself, and disappear and dart out underneath, black and foaming at the gorge and outlet of the pool.

Eleven days were spent in ascending the Essequibo, which was heavy in flood, and detained the party double the time anticipated ; five days brought them from Tomatomari, the lowest fall on the Potaro, to the Patamona village. In this stage there are five cataracts, two of which, at least, are inaccessible. Two days were occupied in visiting the foot and summit of the Fall, and in descending to the Settlement, leaving Messrs. Brown and King to complete the survey and sketches of the country in four days and a half. 